Pak. j. sci. ind. res. Ser. B: biol. sci. 2020 63B(2) 77-85

\title{
Pharmacognostic and Physico-chemical Standardization of Monotheca buxifolia (Falc.) A. DC.
}

\author{
Maryam Ehsan $^{a *}$, Muhammad Ibrara ${ }^{a}$ Fazal Hadia and Barkatullah ${ }^{\mathrm{b}}$ \\ ${ }^{a}$ Department of Botany, University of Peshawar, KPK, Pakistan \\ ${ }^{\mathrm{b}}$ Department of Botany, Islamia College Peshawar, KPK, Pakistan
}

(received September 17, 2018; revised December 12, 2018; accepted December 19, 2018)

\begin{abstract}
Monotheca buxifolia is an ethno-medicinally important plant of Pak-Afghan regions. The pharmacognostic standards of fruit, leaf, seed, barks of stem and root were set in present study. Microscopy revealed characteristic distinguishable powder drug fragments. Each part showed certain unique florescence behaviour with various reagents under light of various wavelengths. It has a broad spectrum phytochemical profile including amino acids and proteins, fats (fixed oils), sugars (both non reducing and reducing), alkaloids, flavonoids, glycosides, tannins, triterpenoids, phenolics, saponins, phytosterols and anthocyanins. The fruit had 15.5\% moisture contents seed and leaf had $8.5 \%$ each and stem and root bark had $9.5 \%$ each. The values of total ash were 7.0, 6.0, 4.5, 8.25 and $11.75 \%$; values of water soluble ash were 4.9, $3.5,0.5,4.2$ and $6.75 \%$, while the values of acid insoluble ash $1.5,1.75,4.0,3.75$ and $4.25 \%$ in fruit pulp, leaf, stem bark, root bark and seeds, respectively. The fixed oil yield of M. buxifolia was measured to be $8.33,10.62$ and $0.56 \%$ in fruit pulp, seeds and leaves, respectively. Palmitic acid, Oleic acid, Linolenic acid, Stearic acid and Myristic acid were the most frequently found fatty acids in each part. The plant is a rich source of phosphorus, nitrogen and potassium. The plant contained safe amounts of tested trace elements as directed by WHO except for cobalt in root bark $(10.7 \pm 0.01)$ and lead in stem bark (22.48 \pm 0.33$)$.
\end{abstract}

Keywords: pharmacognostic, Monotheca buxifolia, drug fragments

\section{Introduction}

Monotheca buxifolia is a short spiny tree widely distributed in the hilly areas of Pakistan and Afghanistan, locally called "gurguray". It has well known ethnobotanical uses as a source of edible fruit, fuel, fodder and medicinal benefits like diuretic, laxative, purgative, refrigerant and haematinic (Rashid and Khan, 2009). M. buxifolia has derived interest of various researchers for different medicinal aspects in the recent years. Anwar et al. (2018) reported the in-vitro antioxidant activity of Ag-capped M. buxifolia (Flac.). It has experimentally proven role in treatment and management of depression and free radicals based disorders (Burki et al., 2018), antipyretic and analgesic activities (Hassan et al., 2017), anti-proliferative activity against the human lung cancer (Javed et al., 2016), inhibitory actions against Urease enzyme activity and potentials of renal tissue protection; significant antipyretic, anti-inflammatory and antinociceptive properties and protective effects against hepatic damage induced by rifampicin and isoniazid (Ullah et al., 2016 a, b and c), hypoglycemic potentials (Javed et al., 2015), in-vitro antioxidant potential and radical scavenging activity (Jan et al., 2013; Rehman

*Author for correspondence; E-mail: jerry_me111@yahoo.com et al., 2013) anthelmintic, antiseptic and antimicrobial activities (Hazrat et al., 2013; Shah et al., 2012).

Keeping in view the immense increase in medicinal importance of this plant the present work is an effort to standardize M. buxifolia, as the purity and quality of any drug assures its effectiveness. By standardizing a drug, constant ratios of bio-active components, uniform potency, and adulteration free drugs are obtained (Fernandez-Bolanos et al., 2006). Pharmacognostic studies help in stepwise standardization of natural drugs especially those of herbal origin by evaluation of their morpho-anatomical and physico-chemical perspectives (Samuelsson and Bohlin, 2017).

\section{Materials and Methods}

Collection and preservation. The plant collections were made from Paito Dara, Lower Dir, Pakistan. It was identified and authenticated from Peshawar University's Department of Botany and a voucher specimen was submitted to the same department (herbarium) for future reference. Rest of specimens were each (fruit, leaf, seeds, stem and root barks) separately washed, dried under shade, ground and packaged in air sealed bottles. 
Powder drug studies. Shade dried powdered specimens of M.buxifolia leaf, fruit, seeds, stem and root barks were examined for physical features like colour, taste and odour. For microscopic study, a small amount of each was individually taken on slide and macerated by boiling in concentrated chloral hydrate solution. Various fragments of powdered drugs were then observed under microscope at $45 \mathrm{X}$ and $10 \mathrm{X}$ resolutions of the objective lens and photographed (Wallis, 1985).

Florescence study. The colour impressions produced by crude aqueous and methanol extracts and powdered drugs of M. buxifolia when observed under daylight and UV lights of different wavelengths (264 $\mathrm{nm}$ and $366 \mathrm{~nm}$ ) both directly and after treating with various reagents $\left(50 \%\right.$ nitric acid $\left(\mathrm{HNO}_{3}\right), 50 \%$ hydrochloric acid $(\mathrm{HCl})$, picric acid, $50 \%$ sulphuric acid $\left(\mathrm{H}_{2} \mathrm{SO}_{4}\right)$, $10 \% \mathrm{FeCl}_{3}$ solution, $\mathrm{NH}_{3}$ solution, iodine solution, $\mathrm{NaOH}$ in water and $\mathrm{NaOH}$ in ethanol) were noted following Nikam et al., (2009).

Preliminary phytochemical profiling. Preliminary qualitative phytochemical screening for proteins, carbohydrates, fats, flavonoids, tannins, alkaloids, glycosides, phenols, phytosterols, anthocyanins, saponins, and terpenoids in various parts of M. buxifolia was carried out following methods given by American Association of Clinical Chemistry (AACC), (2010) and Khandelwal (1998).

Determination of moisture content. Moisture content of the each powdered drug of M. buxifolia (leaf, fruit, seed and barks of stem and root) were determined following methods of Association of Official Agricultural Chemists (AOAC, 2016).

Determination of ash content. Ash values (including total ash, water soluble ash and acid insoluble ash) of the studied parts of M. buxifolia were determined as per the methods given by Jarald and Jarald (2007).

Fixed oil analysis. Following the detections of qualitative phytochemical screening, fixed oils were expressed from fruit, seed and leaves of M. buxifolia and each was subjected to GC-MS analysis to know their fatty acid composition as per methods given by AOAC (2016) and American Oil Chemist's Society (AOCS, 2013).

Elemental analysis. Elemental profile of the studied parts of M. buxifolia was determined through atomic absorption spectrophotometry to detect the amounts potassium $(\mathrm{K})$, nitrogen $(\mathrm{N})$ and phosphorus $(\mathrm{P})$, manganese $(\mathrm{Mn})$, iron $(\mathrm{Fe})$, zinc $(\mathrm{Zn})$, copper $(\mathrm{Cu})$, lead $(\mathrm{Pb})$, chromium $(\mathrm{Cr})$, cobalt $(\mathrm{Co})$, cadmium $(\mathrm{Cd})$ and nickel (Ni) following AOAC, (2016) and Tuzen et al. (2003).

\section{Results and Discussion}

Powder drug studies. Fruit and seed. The dark blackish brown powder of fruit pulp had a sweet fruity odour. It has fragments of epidermis with few stomata and starch granules, fragments of endocarp packed with starch grains and oil globules, prismatic crystals of calcium oxalate and rounded starch grains. The light brown powder of seed had an indistinct odour and bitter taste. Major fragments included isodiametric sclerenchyma cells of testa, parenchyma cells of endosperm with polygonal outlines and aggregated masses within, spiral vessels, parenchyma cells of cotyledons, aggregated grains of starch and variously formed crystals of calcium oxalate (Fig. 1-2).

Leaf. The powdered drug prepared from leaf was dull green in colour and had fragments of upper epidermis having polygonal cells without intercellular spaces, few actinocytic stomata and the attached cylindrical, elongated cells of palisade layer, isodiametric parenchyma cells of spongy mesophyll tissue containing crystals of calcium oxalate, fragments of lower epidermis with trichomes and actinocytic stomata, unicellular nonglandular trichomes (both simple and branched), cuboid and prismatic crystals of calcium oxalate (Fig. 3).

Stem bark. The powdered drug prepared from stem bark of M. buxifolia was light brown in colour and had an indistinct odour and a slightly bitter taste. It had fragments of dark brown, compactly arranged cork cells having thick walls and attached fragments of phallogen, polygonal, brown, thick walled cells of cortex having crystals of calcium oxalate and starch aggregates, isolated thick lignified phloem fibres and some fibres attached with the parenchyma of medullary rays (Fig. 4).

Root bark. The greyish brown powder drug of root bark of M. buxifolia was bitter to taste and had no distinct odour. It had rectangular, dark brown pigmented, thick walled cells of periderm, fragments of cortical cells which were polygonal and pigmented and contained plenty of starch grains, parenchyma cells of medullary ray, perforated xylem vessels and crystals of calcium oxalate (Fig. 5).

Florescence studies. The observations of florescence behaviour of $M$. buxifolia under lights of different wavelengths (nanometres $(\mathrm{nm})$ ) are summarized in Table 1. 


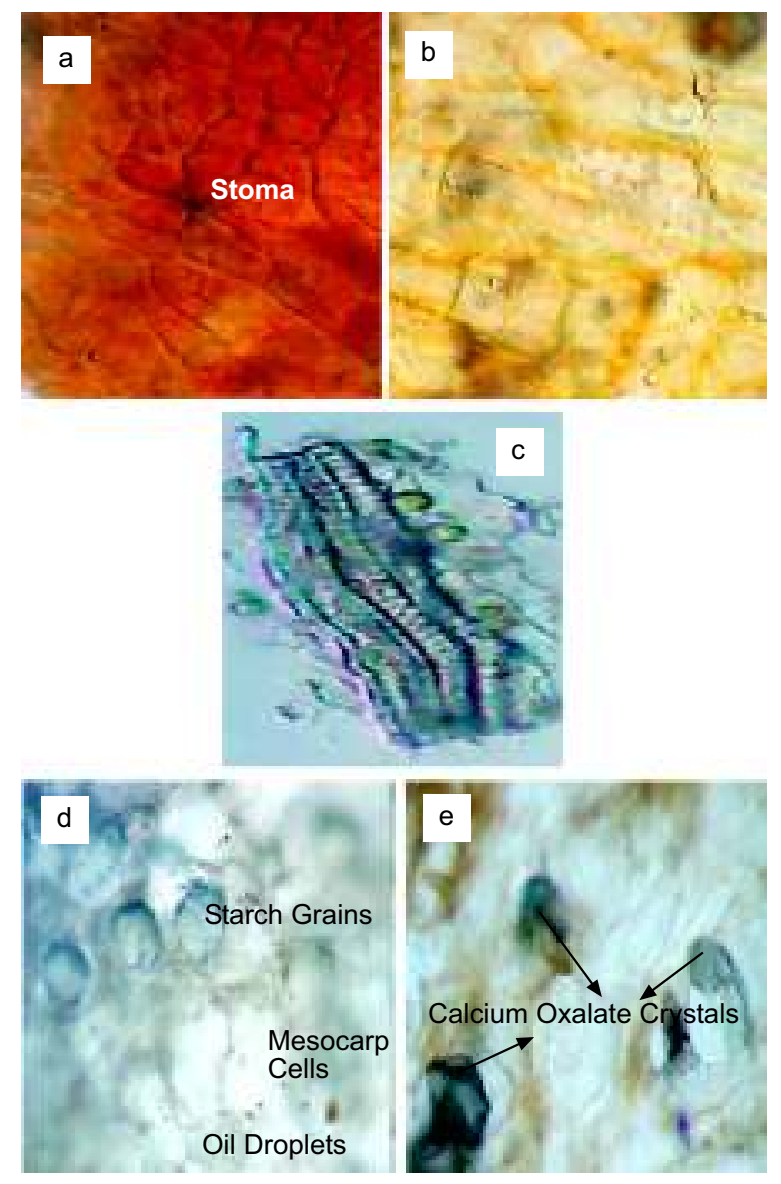

Fig. 1. Characteristic fragments of M. buxifolia fruit powder. (a) Fragments of epidermis with stomata, (b) Fragments of pigmented epicarp filled with oil droplets and starch granules, (c) Spiral vessels, (d) Fragments of mesocarp cells with starch granules and oil globules and (e) Crystals of calcium oxalate.

Phytochemical profile. Both aqueous and methanol extracts of M. buxifolia Fruit pulp, leaf, stem bark and root bark gave positive indications for presence of amino acids, proteins, carbohydrates, flavonoids, phenolic compounds, alkaloids, glycosides, phytosterols, triterpenoids, tannins, anthocyanins, and saponins. Volatile oils were not indicated in any of the tested extracts while fixed oils and fats were detected in fruit pulp, leaf and seed only. Glycosides, anthocyanins and flavonoids were also lacking in the seed extracts. Only the aqueous seed extract gave positive detection for sterols.

Moisture content, ash contents and fixed oil yield. Fixed oil analysis. Seeds of M. buxifolia yielded 10.62\%
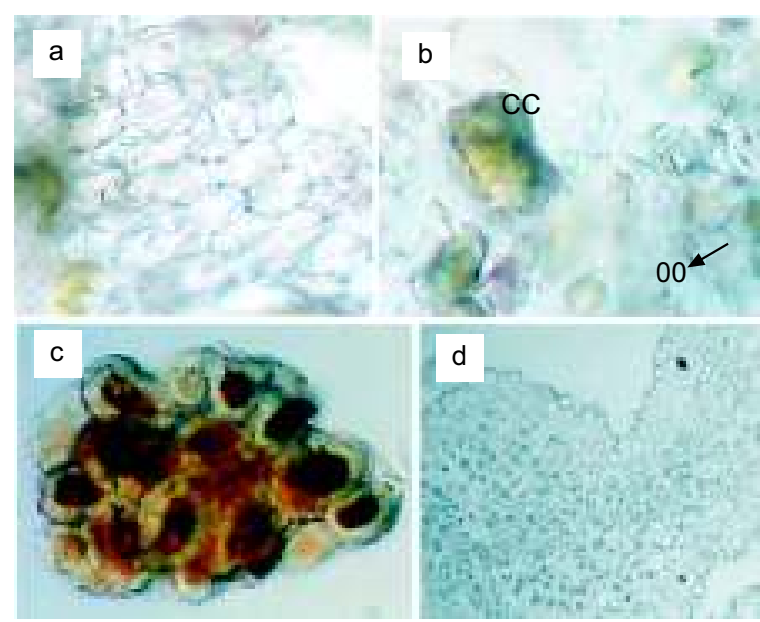

Fig. 2. Characteristic fragments of M. buxifolia seed powder. (a) Thin walled parenchyma cells of cotyledons, (b) Oil droplets (OD) and crystals of calcium oxalate (CC), (c) Sclerenchyma cells of seed coat and (d) Fragments of endosperm.

fixed oils which is the highest percentage among the tested parts, the fruit yielded $8.33 \%$ followed by leaf $0.56 \%$, which was the least of all. GCMS analysis revealed that the fixed oil of seed was composed of 34 fatty acids, major being Linolenic acid (20.73\%), Oleic acid $(20.30 \%)$, Palmitic acid (5.52\%) and Stearic acid (2.074\%). The fixed oil of fruit also had 34 component fatty acids including Myristic acid, Palmitic acid and Oleic acid in 2.53, 2.52 and $1.828 \%$, respectively. Fatty acids of leaf oil included Palmitic acid, Linoleic acid, Oleic acid, Stearic acid and Myristic acid in following percentages 5.008, 3.892, 2.864, 1.506 and $1.163 \%$, respectively.

Elemental analysis. The parts per million (PPM) concentrations of various macro and micro-nutrient elements of M. buxifolia are given in Table 4.

Plants are natural drug industries providing chemical solutions against various health disorders since the start of human civilization. The modern pharmaceutics derive their core potential formulas from chemical essentials of plants (Singh et al., 2002). However, while exploiting a plant as an active drug, manufacturers may come across adulterations, substitutions and false identities. Standardization of crude drugs is a mean to avoid such discrepancies. It helps in identifying the adulterations, impurities and mistaken identities (Pferschy-Wenzig and Bauer, 2015). There are a number of methods for 


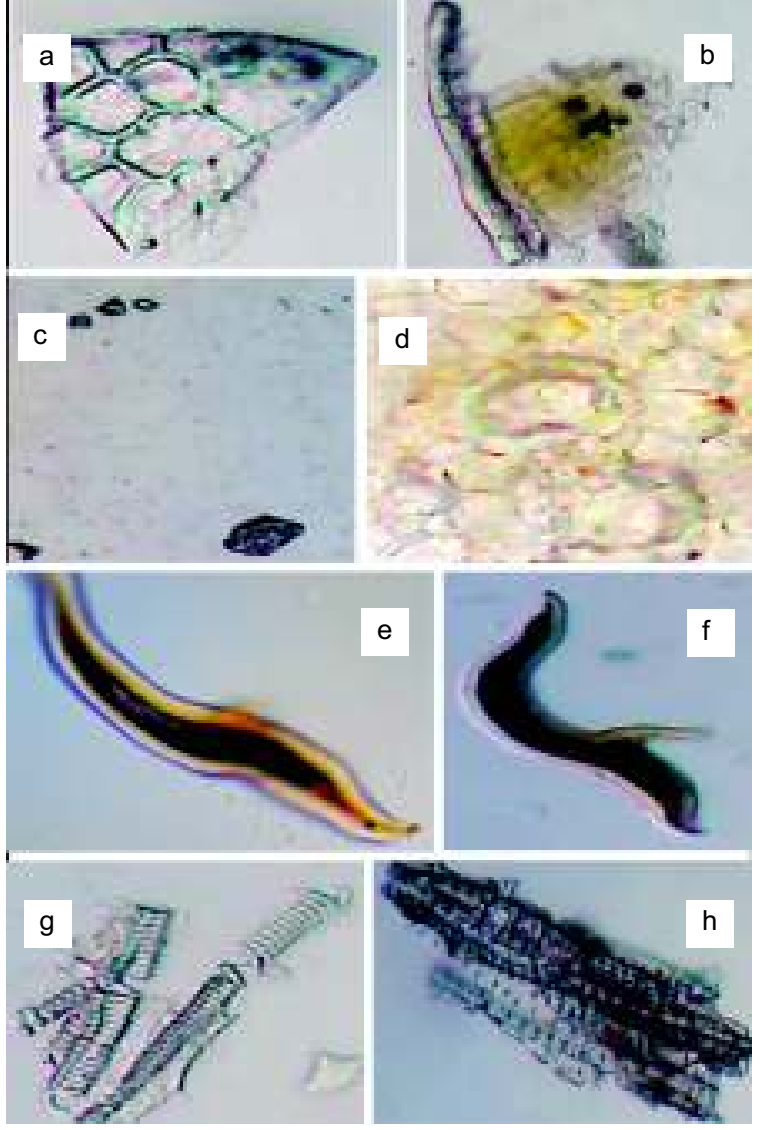

Fig. 3. Fragments of powder drug of Monotheca buxifolia leaf. (a) Upper epidermis, (b) Upper epidermis with palisade cells, (c) Calcium oxalate crystals, (d) Fragments of lower epidermis with actinocytic stomata, (e) Simple unicellular trichome, (f) Forked trichome, (g) Spiral xylem vessels and (h): Simple pitted vessels.

standardization of crude drugs however WHO recommends the pharmacognostic studies to be most reliable in this regard (WHO, 1995). Pharmacognosy provides improved techniques for identification, structural studies and bioassays (Samuelsson and Bohlin, 2017).

A drug of uniform potency which has the same chemical makeup and produces the same pharmacological effect in repeated testing is said to be a standardized drug (Heinrich et al., 2018; Holiman, 1989).

Microscopic studies of powdered drugs also help in finding adulterants and substituents of crude drugs (whether added accidentally or intentionally). These are irrelevant substances including fragments of

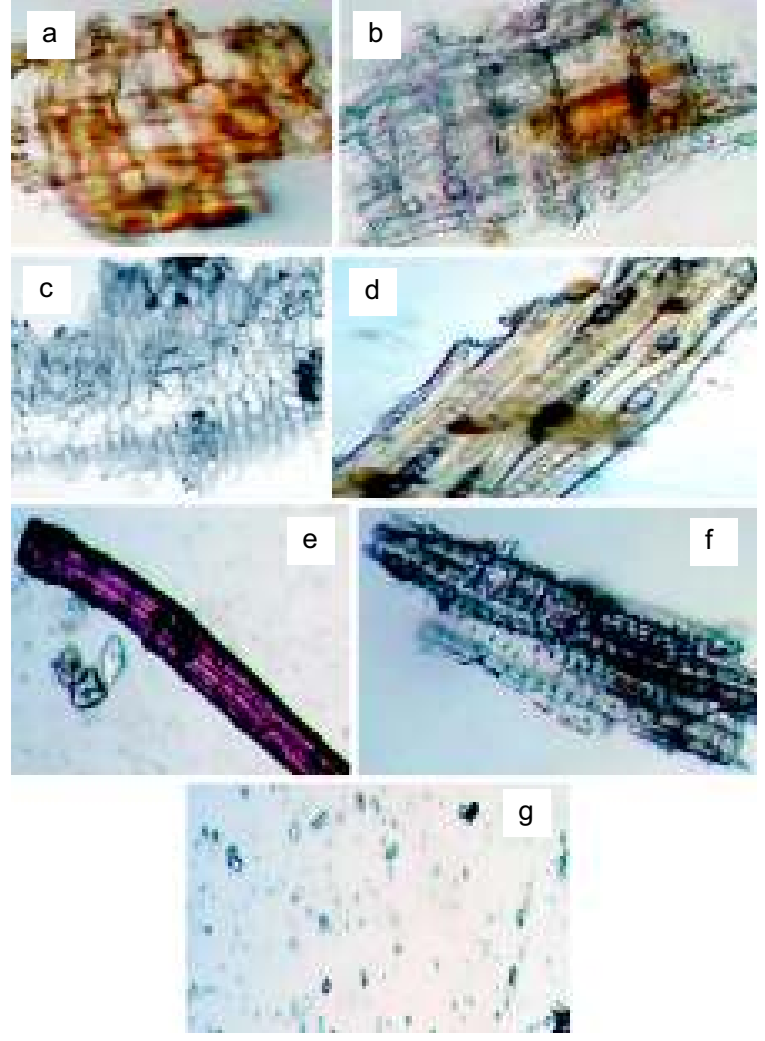

Fig. 4. Fragments of powder drug of Monotheca buxifolia stem bark. (a) Cork cells, (b) Cortical cells containing starch grains, (c) Fragment of periderm, (d) Fibres attached with parenchyma cells of medullary rays, (e) Thick lignified phloem fibre, (f) Vessels and (g) Aggregates of calcium oxalate and Starch granules.

exhausted parts or other plants, microbial spores, dust particles and faecal deposits of small insects etc. (Jarald and Jarald, 2007).

Study of fluorescence behaviour of crude drugs is yet another mean for their standardization since the cut surfaces of such drugs, their extracts and powders have unique phytochemical constituents which produce different characteristic colour hues in UV light. If they are not themselves florescent, re-orientation of the chemical structures into florescent derivatives can be attained by treating them with various chemical reagents. This phenomenon can be used as a standard reference for qualitative identification and indication of adulteration to natural drugs (Zhao et al., 2011; Wallis, 1985). 


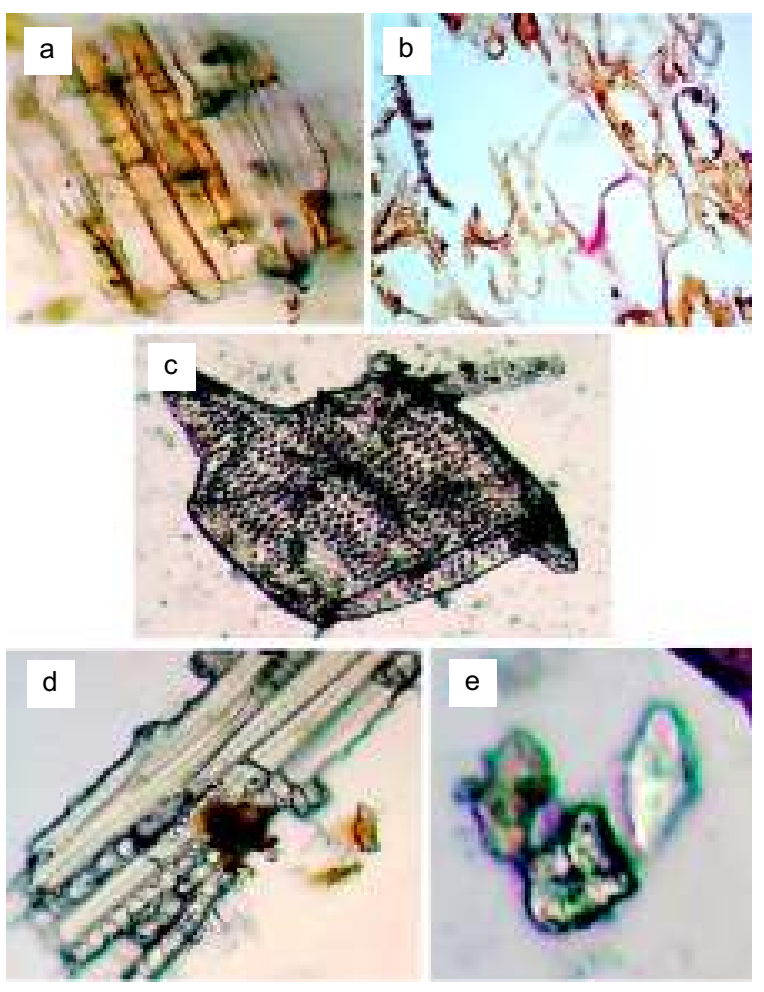

Fig. 5. Characteristic fragments of M. buxifolia root bark. (a) Cork cells, (b) Fragments of cortical cells, (c) Vessel with pitted walls, (d) Fibers attached with Medullary rays and (e) Crystals of calcium oxalate.

During various physiological processes of plants a large number of intermediate secondary metabolites are produced which have potential pharmaceutical actions (Chung et al., 1998). Alkaloids are one such intermediate phytochemicals with preventive potentials against a broad range of cancer types (Jiang et al., 2016). Tannins have remarkable antioxidant and antimicrobial potentials (Chung et al., 1998), saponins help in maintaining levels of sugars and cholesterol in blood. They are also effective against cancers and prevent dental caries (Shi et al., 2004), flavonoids are potential antioxidants, free radical scavengers, antihypertensive and antitumor agents. They also prevent HIV infestations and cardiac disorders (Xiao et al., 2011), terpenoids are natural antiulcer, antimalarial, antimicrobial, anti-hepaticidal, anticancer and diuretic agents (Asadi-Samani et al., 2016; Dudareva et al., 2004), Cardiac glycosides and steroids are used against selective proliferative disorders, congestive cardiac failure and have known anti-arrhythmic actions
(Newman et al., 2008). Evaluation of the biochemical profile of crude drugs may also help in standardization as altered biochemical parameters indicate incidence of substitution, adulteration and low grade drug constituents (Jarald and Jarald, 2007). The present study reveals that $M$. buxifolia contains a broad spectrum of active phytochemical constituents which may individually or in various combinations with other secondary phyto-constituents produce tremendous pharmacological actions.

Moisture contents directly affect the shelf life of dried crude drugs as it supports microbial infestations which need moisture for colonising host surfaces and carrying out their enzyme reactions (Chanda, 2014). Since all the dried powdered drugs prepared from M. buxifolia had low moisture contents (Table 2), they can be safely stored without microbial deteriorations for longer periods during study or for therapeutic purposes.

Determination of ash values is a useful quantitative standard for purity and quality of a drug. They also help in finding adulterated drugs or drugs with mixed identities. Total ash values are evaluated to indicate presence of inorganic earthy matters like lime, chalk or siliceous substances in a drug. Acid insoluble and water soluble ash values indicate the proportions of exhausted drug material and calcium oxalate in a drug, respectively (Jarald and Jarald, 2007). Ash analysis of M. buxifolia revealed that all the parts had low amounts of inorganic, non-physiological matter in them. Seed had highest ash values followed by root bark, fruit, leaf and the lowest of the stem bark (Table 2). These ash constants may be consulted in future for authentic choice and selection of this plant.

Fats and oils store the highest amounts of energy among the major biomolecules. They form a protective seal in body against heat and moisture loss and keep the organs lubricated. Cosmetic, food and pharmaceutical industries use fixed oils along with aromatic oils in a variety of their commercial products particularly related to body and skin care. Fixed oils are composed of a huge range of different fatty acid combinations in varying proportions which impart unique properties and pharmacological potential to each of them (Mohammed and Jorf-Thomas, 2003). These include cure to diseases as complex as chronic hepatic damage to the simple constipation. Inadequately low intake of these may result in 


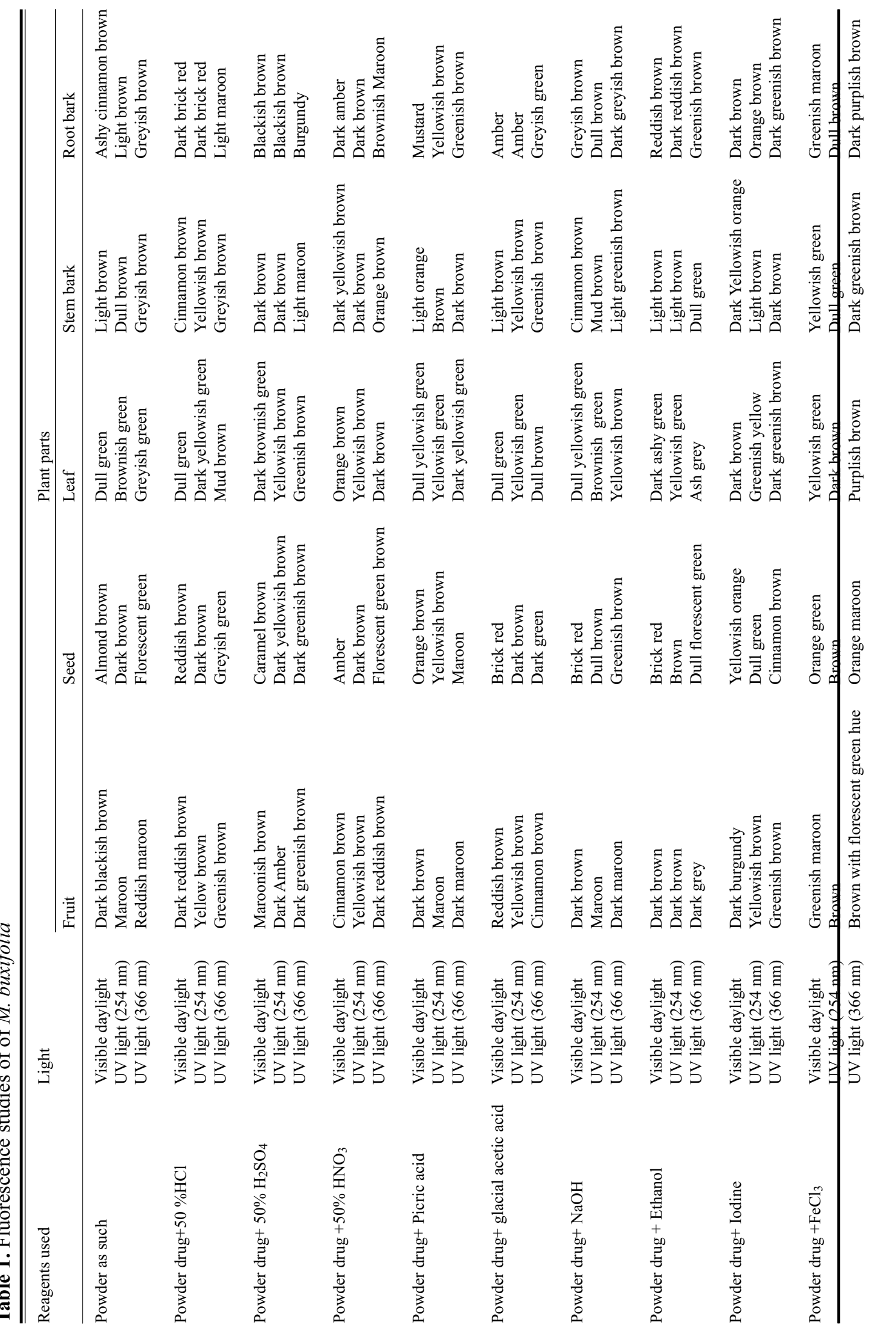


Table 2. Percent moisture contents, ash values (w/w) and fixed oil contents of M. buxifolia

\begin{tabular}{llllll}
\hline \hline Plant part & $\begin{array}{l}\text { Moisture } \\
\text { contents }\end{array}$ & $\begin{array}{l}\text { Total } \\
\text { Ash }\end{array}$ & $\begin{array}{l}\text { Acid } \\
\text { insoluble } \\
\text { Ash }\end{array}$ & $\begin{array}{l}\text { Water } \\
\text { soluble } \\
\text { Ash }\end{array}$ & $\begin{array}{l}\text { Fixed } \\
\text { oil } \\
\text { yield }\end{array}$ \\
\hline Leaf & $8.5 \%$ & $6.0 \%$ & $1.75 \%$ & $3.5 \%$ & $0.56 \%$ \\
Fruit & $15.5 \%$ & $7.0 \%$ & $1.5 \%$ & $4.9 \%$ & $8.33 \%$ \\
Seed & $8.5 \%$ & $11.75 \%$ & $4.25 \%$ & $6.75 \%$ & $10.62 \%$ \\
Root bark & $9.5 \%$ & $8.25 \%$ & $3.75 \%$ & $4.2 \%$ & - \\
Stem bark & $9.5 \%$ & $4.5 \%$ & $4.0 \%$ & $0.5 \%$ & - \\
\hline \hline
\end{tabular}

retarded growth and various deficiency disorders of skin and reproductive system (Benatti et al., 2004; Riechart, 2002). The present study revealed that M. buxifolia contains plenty of fatty acids of huge commercial importance in its seed, fruit and leaves, especially w.r.t cosmetic and pharmaceutical industry. The unsaturated fatty acids were higher in proportion as compared to saturated fatty acids. Saturated fatty acids increase the risks of cardio-vascular disorders due to elevation of blood cholesterol levels. Thus fixed oils obtained from M. buxifolia are safer for medicinal uses (Abed, 2007).

The organic structures of plants contain various nonmetallic and metallic ions as their component parts.
These may be associated with enzyme molecules or in the form of metallo-proteins. Together with phytochemicals they enhance the nutritional and pharmacological significance of plants. These compounds are involved in a number of vital body functions and their deficiency leads to abnormal development of the organism (Morabad et al., 2012). The trace elements despite their low amounts play key role in a plant's nutritional significance and therapeutic potentials. However their excess or prolonged use may pose various health risks due to toxic accumulations in the body (Ibrar et al., 2013). To avoid such encounters WHO (1998) recommends safe doses of heavy metals for human intake. Elemental profile of M. buxifolia analyzed in this work showed that all the parts of this plant contain large amounts of potassium, nitrogen and phosphorus which are component parts of mojor bio-molecules (Table 4). Fruit, seeds and leaves are good source of iron and may be used in anemic conditions. The plant had all the trace elements in safe limits directed by WHO except for cobalt $(10.7 \pm 0.01 \mathrm{ppm})$ in root bark and lead $(22.48 \pm 0.33$ ppm) in stem bark (Table 4). This must be taken care of while consuming these parts.

Conflict of Interest. The authors declare they have no conflict of interest.

Table 4. elemental profile of $M$. buxifolia

\begin{tabular}{|c|c|c|c|c|c|}
\hline \multirow[t]{2}{*}{ Element detected } & \multicolumn{5}{|c|}{ Plant part } \\
\hline & Leaf & Fruit & Seed & Root bark & Stem bark \\
\hline $\mathrm{P}(\mathrm{ppm})$ & $140.63 \pm 0.01$ & $359.4 \pm 0.04$ & $343.8 \pm 0.03$ & $609.4 \pm 0.06$ & $125.0 \pm 0.01$ \\
\hline $\mathrm{N}(\mathrm{ppm})$ & $2800 \pm 1.6$ & $3000 \pm 0.91$ & $2300 \pm 1.62$ & $1200 \pm 0.52$ & $1600 \pm 0.21$ \\
\hline $\mathrm{K}(\mathrm{ppm})$ & $3041.0 \pm 0.30$ & $9711.6 \pm 0.97$ & $2648.6 \pm 0.26$ & $3531.5 \pm 0.35$ & $2158.1 \pm 0.22$ \\
\hline $\mathrm{Fe}(\mathrm{ppm})$ & $1.16 \pm 0.05$ & $1.07 \pm 0.006$ & $2.47 \pm 0.01$ & $0.84 \pm 0.03$ & $0.32 \pm 0.01$ \\
\hline Mn (ppm) & $0.04 \pm 0.003$ & $0.06 \pm 0.005$ & $0.12 \pm 0.002$ & $0.19 \pm 0.009$ & $0.06 \pm 0.006$ \\
\hline $\mathrm{Cu}(\mathrm{ppm})$ & $0.065 \pm 0.001$ & $0.24 \pm 0.01$ & $0.24 \pm 0.004$ & $0.68 \pm 0.005$ & $1.58 \pm 0.009$ \\
\hline $\mathrm{Cr}(\mathrm{ppm})$ & $1.02 \pm 0.07$ & $1.01 \pm 0.19$ & $1.014 \pm 0.12$ & $1.04 \pm 0.03$ & $1.007 \pm 0.05$ \\
\hline $\mathrm{Zn}(\mathrm{ppm})$ & $0.39 \pm 0.02$ & $0.19 \pm 0.009$ & $0.15 \pm 0.01$ & $2.36 \pm 0.008$ & $0.99 \pm 0.006$ \\
\hline $\mathrm{Pb}(\mathrm{ppm})$ & $0.36 \pm 0.18$ & $0.82 \pm 0.19$ & $2.80 \pm 0.33$ & $22.48 \pm 0.33$ & $0.18 \pm 0.03$ \\
\hline Co (ppm) & $-0.13 \pm 0.00$ & $-1.57 \pm 0.14$ & $-0.156 \pm 0.04$ & $-1.23 \pm 0.16$ & $10.7 \pm 0.01$ \\
\hline $\mathrm{Ni}(\mathrm{ppm})$ & $0.70 \pm 0.03$ & $0.75 \pm 0.06$ & $1.16 \pm 0.23$ & $1.58 \pm 0.33$ & $1.05 \pm 0.02$ \\
\hline $\mathrm{Cd}(\mathrm{ppm})$ & ND & $0.02 \pm 0.009$ & $0.01 \pm 0.012$ & $0.01 \pm 0.001$ & $0.016 \pm 0.02$ \\
\hline
\end{tabular}




\section{References}

AACC, International. 2010. Approved Methods of Analysis, $11^{\text {th }}$ edition (online), St. Paul, M. N.

Abed, K.F. 2007. Antimicrobial activity of essential oils of some medicinal plants from Saudi arabia. Saudi Journal of Biological Sciences, 14: 53-60.

Anwar, N., Khan, A., Shah, M., Anwar, S. 2018. Green synthesis of silver nanoparticles using an aqueous extract of Monotheca buxifolia (Flac.) Dcne. Russian Journal of Physical Chemistry, 92: 124131.

AOAC, International. 2016. Official Methods of Analysis, $20^{\text {th }}$ edition, 2016 (online), Rockville.

AOCS, 2013. American Oil Chemist Society. Official Methods and Recommended Practices, $6^{\text {th }}$ edition, $3^{\text {rd }}$ printing, Champaign, IL.

Asadi-Samani, M., Kooti, W., Aslani, E., Shirzad, H. 2016. A systematic review of Iran's medicinal plants with anticancer effects. Journal of EvidenceBased Complementary and Alternative Medicine, 21: 143-153.

Benatti, P., Peluso, G., Nicolai R., Calvani, M. 2004. Polyunsaturated fatty acids: biochemical, nutritional and epigenetic properties. Journal of the American College of Nutrition, 23: 281-302.

Burki, S., Mehjabeen, Burki, Z.G., Shah, Z.A., Imran, M., Khan, M. 2018. Phytochemical screening, antioxidant and in-vivo neuro-pharmacological effect of Monotheca buxifolia (Falc.) extract. Pakistan Journal of Pharmaceutical Sciences, 31: 1519-1528.

Chanda, S. 2014. Importance of pharmacognostic study of medicinal plants: an overview. Journal of Pharmacognosy and Phytochemistry, 2: 69-73.

Chung, K.T., Wong, T.Y., Wei, C.I., Huang, Y.W., Lin, Y. 1998. Tannins and human health: a review. Critical Reviews in Food Science and Nutrition, 38: 421-464.

Dudareva, N., Pichersky, E., Gershenzon, J. 2004. Biochemistry of plant volatiles. Plant Physiology, 135: 1893-1902.

Fernandez-Bolanos, J., Rodriguez, G., Rodriguez, R., Guillen, R., Jimenez, A. 2006. Extraction of interesting organic compounds from olive oil waste. Grasas Y. Aceites, 57: 95-106.

Hassan, S., Yonghui, Z., Xue, Y. 2017. In-vivo pharmacological investigation of Monotheca buxifolia and Bosea amherstiana using animal models. Journal of Biotechnology and Biomaterials. Joint Event on $15^{\text {th }}$ World Congress on Biotechnology and Biotech Industries Meet and $2^{\text {nd }}$ International Conference on Enzymology and Molecular Biology March 2021, 2017, Rome, Italy.

Hazrat, A., Nisar, M., Zaman, S. 2013. Antibacterial activities of sixteen species of medicinal plants reported from Dir Kohistan valley KPK, Pakistan. Pakistan Journal of Botany, 45: 1369-1374.

Heinrich, M., Lardos, A., Leonti, M., Weckerle, C., Willcox, M. 2018. Best practice in research: consensus statement on ethnopharmacological field studies - ConSEFS. Journal of Ethnopharmacology, 211: 329-339.

Holiman, A. 1989. Plants in Medicine. Chelsea Physic Garden. The Chelsea Physic Garden Co Ltd.

Ibrar, M., Muhammad, N., Shah, W., Barkatullah. 2013. Evaluation of trace and toxic heavy metals in selected crude drugs used in Khyber Pukhtonkhawa, Pakistan. Pakistan Journal of Botany, 45: 141-144.

Jan, S., Khan, M.R., Rasheed, U., Bukhari, J. 2013. Assessment of antioxidant potential, total phenolics and flavonoids of different solvent fractions of Monotheca buxifolia fruit. Osong Public Health and Research Perspectives, 4: 246-254.

Jarald, E.E., Jarald, S.E. 2007. A Text Book of Pharmacognosy and Phytochemistry ( $1^{\text {st }}$ edition), pp. 6, CBS Publishers and Distributors, New Delhi, India.

Javed, S., Oise, I.E., Nahar, L., Ismail, F.M.D., Mahmood, Z., Sarker, S.D. 2016. Isolation, identification and antiproliferative activity of triterpenes from the Genus Monotheca A. DC. Records of Natural Products, 10: 782-787.

Javed, S., Hayat, M.F., Ahmad, M., Ahmad, Z. 2015. Hypoglycemic activity of Monotheca buxifolia and isolation of the active constituents through bioassaydirected fractionation techniques. Asian Journal of Agriculture and Biology, Special Issue, CLSRAbstracts, 93.

Jiang, Q.W., Chen, M., Cheng, K., Yu, P., Wei, X., Shi, Z. 2016. Therapeutic potential of steroidal alkaloids in cancer and other diseases. Medicinal Research Reviews, 36: 119-143, Special Issue: Natural Product-based Drug Discovery.

Khandelwal, K.R. 1998. Practical Pharmacognosy: Techniques and Experiments. $4^{\text {th }}$ edition, Nirali Prakashan.

Mohammed, R.F., Jorf-Thomas, M. 2003. Determination of the lipid classes and fatty acid profile of Niger 
seed (Guizotia abyssinica Cass). Phytochemical Analysis, 14: 366-370.

Morabad, R.B., Patil, S.J., Tapash, R.R. 2012. First series transition elemental analysis in some therapeutically important medicinal plants by AAS method. Journal of Materials and Environmental Sciences, 4: 171-176.

Newman, R.A., Yang, P., Pawlus, A.D., Block, K.I. 2008. Cardiac glycosides as novel cancer therapeutic agents. Molecular Interventions, 8: 36-49.

Nikam, D.D., Jaiswal, Y.S., Jirge, S.S., Chaudhary, Y. 2009. Pharmacognostic evaluation of the leaves of Sesbania sesban (1). Journal of Research and Education in Indian Medicine, 25: 19-24.

Pferschy-Wenzig, E., Bauer, R. 2015. The relevance of pharmacognosy in pharmacological research on herbal medicinal products. Epilepsy and Behavior, 52: 344-362.

Rashid, A., Khan, S.M. 2009. Ethnobotanical study of the important wild plants of Bahadur Khel track (Tehsil Banda Daud Shah) in Karak District. (Unpublished).

Rehman, J., Khan, I.U., Farid, S., Kamal, S., Aslam, N. 2013. Phytochemical screening and evaluation of in-vitro antioxidant potential of Monotheca buxifolia. E3 Journal of Biotechnology and Pharmaceutical Research, 4: 54-60.

Riechart, R.D. 2002. Oil seed medicinals in natural drugs and dietary supplements - new functional foods. Trends in Food Science and Technology, 13: 353-360.

Samuelsson, G., Bohlin, L. 2017. Pharmacognosy. In: Drugs of Natural Origin: A Treatise of Pharmacognosy, (Edition 7) pp. 808. CRC Press Inc. London, UK.

Shah, S.M.H., Shah, S.M.M., Nisar, M., Khan, F.A., Ali, M., Khan, I., Shah, S.M.S., Afridi, M.S., Ali, I. 2012. Antimicrobial activities of medicinal plants used in folk remedies in Pakistan. Journal of Pharmacy Research, 5: 2057-206.

Shi, J., Arunasalam, K., Yeung, D., Kakuda, Y., Mittal, G., Jiang, Y. 2004. Saponins from edible legumes: chemistry, processing, and health benefits. Journal of Medicinal Food, 7: 67-78.

Singh, V.K., Govil, J.N., Singh, G. 2002. Recent progress in medicinal plants: vol. I, Ethnomedicine and Pharmacognosy. In: Ethnopharmacognostical Studies on Panicum repens L. (Kumar, K.). SciTech publishing LLC, 337-344.

Tuzen, M., Turkekul, I., Hasdemir, E., Mendil, D., Sari, H. 2003. Atomic absorption spectrometric determination of trace metal contents of mushroom samples from Tokat, Turkey. Analytical Letters, 36: 14011410 .

Ullah, I., Khan, J.A., Adhikari, A., Khan, A., Hannan, P.A., Wadood, A. Farooq, U. 2016 a. Bioassayguided isolation of new urease inhibitory constituents from Monotheca buxifolia (Falc.) fruit and their molecular docking studies. Records of Natural Products, 10: 744.

Ullah, I., Khan, J.A., Shahid, M., Khan, A., Adhikari, A., Hannan, P.A., Javed, I., Shakeel, F., Farooq, U. 2016 b. Pharmacological screening of Monotheca buxifolia (Falc.) A.DC. for antinociceptive, antiinflammatory and antipyretic activities. $B M C$ Complementary and Alternative Medicine, 5: 273.

Ullah, I., Khan, J.A., Adhikari, A., Shahid, M. 2016 c. Hepatoprotective effect of Monotheca buxifolia fruit against antitubercular drugsinduced hepatotoxicity in rats. Bangladesh Journal of Pharmacology, 11: 248-56.

Wallis, T.E. 1985. Text Book of Pharmacognosy. $5^{\text {th }}$ edition. CBS Publisher and Distributors, New Delhi, India.

World Health Organization (WHO). 1995. Inorganic Lead. Geneva, (Environmental Health).

Xiao, Z.P., Peng, Z.Y., Peng, M.J., Yan, W.B., Ouyang, Y.Z., Zhu, H.L. 2011. Flavonoids health benefits and their molecular mechanism. Mini Reviews in Medicinal Chemistry, 11: 169-177.

Zhao, Z., Liang, Z., Guo, P. 2011. Macroscopic identification of Chinese medicinal materials, traditional experiences and modern understanding. Journal of Ethnopharmacology, 131: 556-561. 